\title{
HUBUNGAN ANTARA LETAK LESI DERMATITIS SEBOROIK DENGAN ANGKA KEJADIAN DERMATITIS SEBOROIK DI POLIKLINIK KULIT DAN KELAMIN RSUD DR. H. ABDUL MOELOEK BANDAR LAMPUNG TAHUN 2017-2019
}

\author{
Anggunan ${ }^{1}$, Eka Silvia ${ }^{2}$, , Arief Effendi ${ }^{3}$, Farahiyah Karamina Kartono ${ }^{4}$ \\ ${ }^{1}$ Departemen Kimia Medik, Fakultas Kedokteran, Universitas Malahayati \\ ${ }^{2}$ Departemen Fisiologi, Fakultas Kedokteran, Universitas Malahayati \\ ${ }^{3}$ Departemen Dermatovenerologi Rumah Sakit Umum Daerah Dr. H. Abdul \\ Moeloek \\ 4Program Studi Kedokteran Umum, Fakultas Kedokteran, Universitas Malahayati
}

[email korespondensi : Karaminafarahiyah@gmail.com]

\begin{abstract}
The Relationship Between the Location of Seborrheic Dermatitis Lesions and the Rate of Seborrheic Dermatitis in the Skin and Gender Clinic Region Public hospital Dr. H. Abdul Moeloek Bandar Lampung in 2017-2019 Seborrheic dermatitis is a chronic papulosquamosa skin disorder that often occurs on the scalp, sebaceous follicular areas on the face and chest. The location of lesions in seborrheic dermatitis is grouped into three major parts, namely seborrheic face, seborrheic body and sidelines, and seborrheic head. This study was conducted to determine the relationship between the location of seborrheic dermatitis lesions with the incidence of seborrheic dermatitis in the Skin and Gender Clinic of RSUD Dr. H. Abdul Moloek Bandar Lampung in 2019.This study uses across-sectional, quantitative, analytic methods with secondary data collection of seborrheic dermatitis. Sampling uses a total sampling technique. Data collection was carried out by recording data in the form of seborrheic dermatitis lesions and analyzed using the Spearman correlation test. The results Obtained209 respondents according to the sample. In DS patients the most frequent location of lesions was $63 \%$ of seborrheic bodies, $21 \%$ of seborrheic faces. Seborrheic head as much as $12 \%$ and seborrheic ear as much as $4 \%$. Spearman correlation test results obtained $p=0.006(p<0.05)$ which means there is a significant relationship between the location of seborrheic dermatitis lesions with the incidence of seborrheicdermatitis.From this study we can conclude there was significant relationship between the location of seborrheic dermatitis lesions with the incidence of seborrheic dermatitis in the skin and genital clinic of RSUD Dr. H. Abdul Moeloek Bandar Lampung ( $p=0.006)$.
\end{abstract}

Keywords: Location of Lesions, Dermatitis, Seborrheic

\section{Abstrak : Hubungan Antara Letak Lesi Dermatitis Seboroik Dengan Angka Kejadian Dermatitis Seboroik Di Poliklinik Kulit Dan Kelamin RSUD Dr. H. Abdul Moeloek Bandar Lampung Tahun 2017-2019}

Dermatitis seboroik merupakan kelainan kulit kronis papulo skuamosa yang sering terjadi pada kulit kepala, daerah folikel sebasea di wajah dan dada.Letak lesi pada dermatitis seboroik dikelompokkan menjadi tiga bagian besar yaitu seboroik wajah, seboroik badan dan sela-sela, serta seboroik kepala. Penelitian ini dilakukan untuk mengetahui hubungan antara letak lesi dermatitis seboroikdenganangka kejadian dermatitis seboroikdi Poliklinik Kulit dan Kelamin RSUD Dr. H. Abdul Moloek Bandar Lampung tahun 2019. Penelitian ini menggunakan metode cross-sectional, kuantitatif, analitik dengan pengumpulan data sekunder dermatitis seboroik. Pengambilan sampel menggunaka nteknik total sampling. Pengumpulan data dilakukan dengan pencatatan data berupa letak lesi dermatitis seboroik serta dianalisis menggunakan uji korelasi Spearman. Hasil Penelitian didapatkan dari 209 
responden sesuai sampel. Pada penderita DS frekuensi letak lesi terbanyak adalah seboroik badan sebanyak $63 \%$, seboroik wajah sebanyak $21 \%$. seboroik kepalasebanyak $12 \%$ dan seboroik telinga sebanyak $4 \%$. Hasil uji statistik korelasi Spearman diperoleh $p=0,006 \quad(p<0,05)$ yang berartiterdapathubungan yang signifikan antara letak lesi dermatitis seboroik dengan angka kejadian dermatitis seboroik. Pada penelitian ini dapat disimpulkan bahwa terdapat hubungan yang signifikan antara letak lesi dermatitis seboroik dengan angka kejadian dermatitis seboroik di poliklinik kulit dan kelamin RSUD Dr. H. Abdul Moeloek Bandar Lampung $(p=0,006)$.

Kata kunci : Letak Lesi, Dermatitis, Seboroik

\section{PENDAHULUAN}

dermatosis

Dermatitis seboroik (DS) adalah kronik

papuloskuamosayang sering ditemukan pada usia bayi dan dewasa, dikaitkan dengan peningkatan kelenjar sebum (seborrhoea) yang aktif, seperti pada kulit kepala, wajah, telinga dan dapat meluas ke dada dan daerah popok (Hajar, 2015). Malassezia furfur (pityrosporum ovale) mungkin merupakan faktor penyebab, tetapi faktor genetik dan lingkungan tampaknya mempengaruhi timbulnya perjalanan penyakit tersebut (Habif, 2016).

Prevalensi dermatitis seboroik di dunia adalah 3-5\% (Selden dkk, 2014). Di Amerika, data mengenai prevalensi dermatitis seboroik adalah sekitar 13\% (Burns dkk, 2010). Sebuah penelitian yang dilakukan di India melaporkan bahwa $18,7 \%$ kasus DS pada bagian kulit kepala terjadi pada orang dewasa dan $13,4 \%$ dari anakanak berusia kurang dari 5 tahun mengalami dermatitis seboroik, dengan puncak prevalensinya selama masa bayi dan menurun terus seiring dengan bertambahnya usia (Cheong dkk, 2016).

Di Singapura prevalensi dermatitis seboroik yaitu $3,2 \%$ pada anak-anak dan $7,0 \%$ pada orang dewasa. Penduduk Asia yang berusia 12-20 tahun memiliki prevalensi dermatitis seboroik yang bervariasi berdasar kota dan negara (misalnya, Macao 2,7\%, Guangzhou 2,9\%, Malaysia 17,2\%, dan Indonesia 26,5\%). Di Jepang dilakukan penelitian cross-sectional dan hasilnya menunjukkan dari 67.448 pasien yang datang ke rumah sakit bagian dermatologi, terdapat $3,28 \%$ pasien dengan DS. Prevalensi yang diperoleh dalam penelitian ini sangat bervariasi, hal ini menunjukkan variabilitas yang tinggi dari DS (Cheong dkk, 2016).

Dalam suatu penelitian yang pernah dilakukan secara acak pada anak usia 12-20 tahun di Indonesia, diperkirakan prevalensi dermatitis seboroik sebesar $10,17 \%$, sedangkan golongan usia 20 tahun ke atas prevalensi didapatkan sebesar $26,45 \%$ (Sampaio dkk, 2011). Prevalensi dermatitis di Indonesia cukup tinggi $(6,78 \%)$, tertinggi di Provinsi Kalimantan Selatan (11,3\%), diikuti Sulawesi Tengah (10,58\%), DKI Jakarta $(9,99 \%)$, Nusa Tenggara Timur $(9,99 \%)$, Nanggroe Aceh Darussalam $(9,87 \%)$. Prevalensi terendah terdapat di Provinsi Sulawesi Barat $(2,57 \%)$ sedangkan Lampung (4,03\%) (Riskesdas, 2007). Sedangkan di RSUD Dr. H. Abdul Moeloek Bandar Lampung setiap bulan ada sekitar 15 penderita dermatitis seboroik berobat (Ahmed dkk, 2013).

Letak lesi pada dermatitis seboroik dikelompokkan menjadi tiga bagian besar yaitu seboroik wajah, seboroik badan dan sela-sela, serta seboroik kepala (Harahap, 2015). Letak lesi yang seringkali terkena di daerah kulit kepala berambut, alis, lipat nasolabial, telinga, liang telinga, bagian atas-tengah dada, punggung, lipat gluteus, inguinal, genital, dan ketiak. Serta sangat jarang menjadi luas dan dapat ditemukan skuama kuning berminyak, eksematosa ringan, kadang kala disertai rasa gatal dan menyengat 
(Jacoeb, 2015). Seboroik muka pada daerah berambut, dijumpai skuama yang berminyak dengan warna kekuning-kuningan sehingga rambut saling melengket; kadang-kadang dijumpai krusta yang disebut Pityriasis Oleosa (Pityriasis steatoides). Kadangkadang skuamanya kering dan berlapis-lapis dan sering lepas sendiri, disebut pitiriasis sika (ketombe). Bisa pula jenis seboroik ini menyebabkan rambut rontok, sehingga terjadi alopesia dan rasa gatal. Perluasan bisa sampai ke belakang telinga (retro aurikularis). Bila meluas, lesinya dapat sampai ke dahi, disebut korona seboroik. Dermatitis seboroik yang dijumpai pada kepala bayi disebut topi buaian atau cradle cap (Harahap, 2015).

Seboroik wajah pada daerah mulut, palpebra, sulkus nasolabial, dagu, dan lain-lain terdapat makula eritem, yang di atasnya dijumpai skuama berminyak berwana kekuningkuningan. Bila sampai ke palpebra, bisa terjadi blefaritis. Sering dijumpai pada wanita. Bila didapati di daerah berambut, seperti dagu dan atas bibir, dapat terjadi folikulitis. Hal ini sering dijumpai pada laki-laki yang sering mencukur janggut dan kumisnya. Seboroik muka di daerah jenggot disebut sikosis barbe (Harahap, 2015).

Seboroik badan Jenis ini mengenai daerah presternal, interskapula, ketiak, inframamma, umbilikus, krural (lipatan paha, perineum, nates). Dijumpai ruam berbentuk makula eritema yang pada permukaannya ada skuama berminyak berwarna kekuning-kuningan. Pada daerah badan, lesinya bisa berbentuk seperti lingkaran dengan penyembuhan sentral. Di daerah intertrigo, kadangkadang bisa timbul fisura sehingga menyebabkan infeksi sekunder (Harahap, 2015).

Menurut penelitian Fadila dkk 2014, terdapat hubungan antara letak lesi dengan kualitas hidup pasien dematitis seboroik. Namun demikian terdapat beberapa penelitian yang menyatakan letak lesi dermatitis seboroik mirip dengan psoriasis dan dermatitis atopik yang biasanya terdapat pada lokasi-lokasi yang mengandung banyak kelenjar sebasea, seperti wajah, badan, dan kepala (Plewig dan Jansen, 2008).

Dari hasil pre-survey yang dilakukan peneliti pada hari Rabu, 25 September 2019 di RSUD Dr. H. Abdul Moeloek Provinsi Lampung kasus DS pada tahun 2017-2019 terdapat 367 kasus, dengan masing-masing 174 kasus pada tahun 2017, 106 kasus pada tahun 2018, dan 87 kasus pada tahun 2019.

Berdasarkan hal tersebut di atas, maka dengan letak lesi DS yang sering terjadi pada lokasi yang mengandung kelenjar sebasea, peluang untuk terjadinya dermatitis seboroik. Oleh karena itu untuk membuktikan hal ini, akan dilakukan penelitian mengenai hubungan antara letak lesi dermatitis seboroik dengan angka kejadian dermatitis seboroik di Poliklinik Kulit dan Kelamin RSUD Dr. H. Abdul Moeloek Bandar Lampung Tahun 20172019.

\section{METODE}

Penelitian ini menggunakan metode analitik observasional yaitu penelitian yang menjelaskan adanya hubungan antara variabel melalui pengujian hipotesa yang dilakukan dengan observasi terhadap variabel yang dilakukan dengan pendekatan kuantitatif. Survei dilakukan untuk mengetahui hubungan antara letak lesi dermatitis seboroik dengan angka kejadian dermatitis seboroik di poliklinik kulit dan kelamin RSUD Dr. H. Abdul Moeloek.

Rancangan penelitian ini menggunakan analitik observasional dengan pendekatan cross-sectional yaitu pengukuran terhadap variabel dilakukan pada waktu bersamaan. Populasi dalam penelitian ini adalah seluruh penderita dermatitis seboroik dan dermatitis atopik pada tahun 20172019 yang diambil dari rekam medisdi Poliklinik Kulit dan Kelamin RSUD Dr. H. Abdul Moeloek Bandar Lampung.

Pengambilan sampel menggunakan teknik total sampling, 
yaitu sampel yang diambil dari keseluruhan total populasi. Metode penelitian besar sampel terhadap populasi diambil jumlah sampel yang dibagi dalam kategori sesuai dengan kriteria inklusi dan kriteria eksklusi. Juga mempertimbangkan syarat penelitian perbandingan, yaitu $n 1=n 2$. Sehingga didapatkan sebanyak 209 orang dengan dermatitis seboroik sebanyak 75 orang dan dermatitis atopik sebanyak 134 orang. Pengumpulan data variabel dependen (Angka Kejadian Dermatitis Seboroik) dan variabel independen (Letak Lesi) dilakukan dengan pengambilan data sekunder yang bersumber dari lembar observasi rekam medik. Alat ukur yang digunakan adalah alat tulis untuk mencatat, melaporkan hasil penelitian dan lembar observasional rekam medik pasien. yaitu:

Kriteria inklusi pada penelitian ini

1) Adanya rekam medik pasien yang terdiagnosis dermatitis seboroik dan dermatitis atopik.

2) Adanya data rekam medik yang menjelaskan letak lesi pasien atopik.

Kriteria eksklusi pada penelitian ini yaitu:

1) Data rekam medik pasien dermatitis seboroik dan dermatitisatopik yang tidak lengkap atau tidak menjelaskan letak lesi pasien.

2) Pasien menderita penyakit kronis lain seperti : HIV/AIDS, parkinson, depresi, tardive dyskinesia, paralisis saraf, transplantasi organ, malignansi, pankreatitis, alkoholik kronik dan hepatitis.

Variabel independen dalam penelitian adalah letak lesi dermatitis seboroik. Sedangkan variabel dependennya adalah angka kejadian dermatitis seboroik. Keduannya didapatkan dari lembar observasonal rekam medik.

Analisa Univariat bertujuan untuk menyajikan secara deskriptif dari variabel-variabel yang diteliti. Analisis bersifat univariat untuk melihat distribusi frekuensi dan presentase dari seluruhfaktor yang terdapat dalam variabel masing-masing, baik variable bebas maupun variabel tergantung.

Analisis bivariat dilakukan dengan uji normalitas. Jika berdistribusi normal, maka menggunakan uji statistik Pearson, yaitu uji yang digunakan untuk mengetahui adanya hubungan dua variabel tersebut bermakna atau tidak bermakna. Uji ini untuk mengetahui hubungan antara letak lesi dengan angka kejadian dermatitis seboroik. Namun jika tidak terdistribusi normal, maka menggunakan uji korelasi Spearman.

\section{HASIL}

Penelitian ini dilaksanakan di Poliklinik Kulit dan Kelamin RSUD Dr. $\mathrm{H}$. Abdul Moeloek Bandar lampung di bulan Desember 2019 sampai dengan selesai. Data ini didapat dari hasil observasi rekam medik pasien dermatitis seboroik dan dermtitis atopik di Poliklinik Kulit dan Kelamin RSUD Dr. H. Abdul Moeloek Bandar Lampung. Pada penelitian ini didapatkan sampel penelitian sebanyak 209 responden.

Berdasarkan tabel 1 di bawah menunjukkan bahwa distribusi frekuensi dermatitis seboroik berdasarkan jenis kelamin pada lakilaki sebanyak 41 orang (55\%) dan pada perempuan sebanyak 34 orang $(45 \%)$. Dan frekuensi dermatitis atopik berdasarkan jenis kelamin pada lakilaki sebanyak 58 orang $(43 \%)$ dan pada perempuan 76 orang $(57 \%)$.

Berdasarkan tabel 2 di bawah menunjukan bahwa distribusi frekuensi dermatitis seboroik berdasarkan kelompok usia yaitu 0-5 tahun sebanyak 4 orang $(5 \%), 6-11$ tahun sebanyak 1 orang (1\%), 12-16 tahun sebanyak 2 orang (3\%), 17-25 tahun sebanyak 14 orang (19\%), 26-35 tahun sebanyak 11 orang (15\%), 3645 tahun sebanyak 17 orang (23\%), 46-55 tahun sebanyak 5 orang $(7 \%)$, 56-65 tahun sebanyak 7 orang (9\%), dan >65 tahun sebanyak 14 orang (19\%). 
Tabel 1. Distribusi Frekuensi Jenis Kelamin Responden

\begin{tabular}{|c|c|c|c|c|c|}
\hline \multirow{2}{*}{ Jenis Kelamin } & \multicolumn{2}{|c|}{ DS } & \multicolumn{2}{|c|}{ DA } & \multirow{2}{*}{ Jumlah } \\
\hline & $\mathbf{N}$ & $\%$ & $\mathbf{N}$ & $\%$ & \\
\hline Laki-laki & 41 & 55 & 58 & 43 & 99 \\
\hline Perempuan & 34 & 45 & 76 & 57 & 110 \\
\hline Jumlah & 75 & 100 & 134 & 100 & 209 \\
\hline
\end{tabular}

Tabel 2. Distribusi Frekuensi Usia Responden

\begin{tabular}{cccccc}
\hline \multirow{2}{*}{ Usia (Thn) } & \multicolumn{3}{c}{ DS } & \multicolumn{3}{c}{ DA } & \multirow{2}{*}{ Jumlah } \\
\cline { 2 - 5 } & $\mathbf{N}$ & $\mathbf{\%}$ & $\mathbf{N}$ & $\mathbf{\%}$ & \\
\hline $0-5$ & 4 & 5 & 29 & 22 & 33 \\
$6-11$ & 1 & 1 & 10 & 7 & 11 \\
$12-16$ & 2 & 3 & 16 & 12 & 18 \\
$17-25$ & 14 & 19 & 24 & 18 & 38 \\
$26-35$ & 11 & 15 & 9 & 7 & 20 \\
$36-45$ & 17 & 23 & 11 & 8 & 28 \\
$46-55$ & 5 & 7 & 13 & 10 & 18 \\
$56-65$ & 7 & 9 & 10 & 7 & 17 \\
$>65$ & 14 & 19 & 12 & 9 & 26 \\
\hline Jumlah & $\mathbf{7 5}$ & $\mathbf{1 0 0}$ & $\mathbf{1 3 4}$ & $\mathbf{1 0 0}$ & $\mathbf{2 0 9}$ \\
\hline
\end{tabular}

Tabel 3. Distribusi Frekuensi Letak Lesi

\begin{tabular}{ccccccc}
\hline \multirow{2}{*}{ Letak Lesi } & \multicolumn{2}{c}{ DS } & \multicolumn{3}{c}{ DA } & \multirow{2}{*}{ Jumlah } \\
\cline { 2 - 5 } & $\mathbf{N}$ & $\mathbf{\%}$ & $\mathbf{N}$ & $\mathbf{\%}$ & \\
\hline Badan & 47 & 63 & 74 & 55 & 121 \\
Kepala & 9 & 12 & 23 & 17 & 32 \\
Telinga & 3 & 4 & 5 & 4 & 8 \\
Wajah & 16 & 21 & 32 & 24 & 48 \\
\hline Jumlah & $\mathbf{7 5}$ & $\mathbf{1 0 0}$ & $\mathbf{1 3 4}$ & $\mathbf{1 0 0}$ & $\mathbf{2 0 9}$ \\
\hline
\end{tabular}

Berdasarkan tabel 3 diatas menunjukan bahwa distribusi frekuensi responden berdasarkan letak lesi pada dermatitis seboroik yaitu seboroik badan sebanyak 47 orang $(63 \%)$, seboroik kepala sebanyak 9 orang $(12 \%)$, seboroik telinga sebanyak 3 orang $(4 \%)$, seboroik wajah sebanyak 16 orang $(21 \%)$. Sedangkan pada dermatitis atopik yaitu seboroik badan sebanyak 74 orang $(55 \%)$, seboroik kepala sebanyak 23 orang (17\%), seboroik telinga sebanyak 5 orang $(4 \%)$, dan seboroik wajah sebanyak 32 orang (24\%). 
Tabel 4. Distribusi Frekuensi Angka Kejadian

\begin{tabular}{ccc}
\hline AngkaKejadian & Frekuensi & Persentase \\
\hline DS & 75 & $36 \%$ \\
DA & 134 & $64 \%$ \\
\hline Jumlah & $\mathbf{2 0 9}$ & $\mathbf{1 0 0} \%$ \\
\hline
\end{tabular}

Berdasarkan tabel 4 diatas menunjukan bahwa distribusi frekuensi angkakejadian DS sebanyak 75 orang $(36 \%)$ dan angka kejadian DA sebanyak 134 orang (64\%). Pengumpulan dan pengolahan data untuk melihat kemaknaan hubungan antara letak lesi dermatitis seboroik dengan angka kejadian dermatitis seboroik.

Berdasarkan hasil pengujian didapatkan data tidak terdistribusi normal, maka uji bivariat untuk mencari hubungan menggunakan prinsip statistik alternatif yaitu $U j \mathrm{ji}$ Korelasi Spearman dan diperoleh data sebagai berikut:

Tabel 5.Hasil Analisis Uji Korelasi Spearman

\begin{tabular}{cccc}
\hline Spearman's rho & $\mathbf{N}$ & Nilai p & $\begin{array}{c}\text { Correlation } \\
\text { Coefficient }\end{array}$ \\
\hline $\begin{array}{c}\text { LetakLesi } \\
\text { AngkaKejadian DS }\end{array}$ & 75 & 0,006 & $-178-1$ \\
\hline
\end{tabular}

Berdasarkan tabel 5 di atas diketahui hasil uji statistik dengan Spearman diperoleh $p$-value $=0,006$ $(p<0,05)$ yang berarti terdapat hubungan yang signifikan antara letak lesi dermatitis seboroik dengan angka kejadian dermatitis seboroik.

\section{PEMBAHASAN}

Pada penelitian ini didapatkan jumlah responden laki-laki lebih tinggi daripada perempuan. Hal ini dapat terjadi karena DS lebih sering terjadi pada laki-laki dibanding perempuan pada semua rentang usia yang menunjukkan adanya kemungkinan hubungan dermatitis seboroik dengan hormon seks seperti androgen (Sampaio dkk, 2011). Hal ini mungkin didukung juga dari produksi hormon androgen yang merangsang atau mengontrol perkembangan dan pemeliharaan karakteristik laki-laki (Schwartz dkk, 2006).

$$
\text { Pada penelitian ini juga }
$$

didapatkan tiga golongan usia terbanyak menderita DS yaitu golongan usia 17-25 tahun sebesar $19 \%$, golongan usia 26-35 tahun sebesar $15 \%$ dan golongan usia 36-45 tahun yang paling banyak menderita DS sebesar $23 \%$. Hal ini mungkin akibat aktivitas kelenjar sebasea mencapai puncaknya pada awal pubertas (Berk, 2010).

Dikatakan juga bahwa insidens dermatitis seboroik mempunyai dua puncak, yang pertama pada bayi pada tiga bulan pertama kehidupan dan puncak yang kedua biasanya terjadi pada usia dekade ke $4-7$ kehidupan (Burns dkk, 2010).

Hasil ini sesuai dengan teori yang peneliti dapatkan bahwasanya letak lesi mempengaruhi angka kejadian DS karena pada daerahdaerah aktivitas kelenjar sebasea berlebih seperti wajah, kepala, dan badan memperbesar kejadian DS. Hal ini sejalan dengan beberapa penelitian yang menyatakan letak lesi dermatitis seboroik biasanya terdapat pada lokasi-lokasi yang mengandung banyak kelenjar sebasea, seperti 
wajah, badan, dan kepala (Plewig dan Jansen, 2008). Hal ini berhubungan dengan peningkatan produksi sebum (sebasea atau seborrhea) yang letaknya paling banyak di kulit kepala dan daerah folikel kayasebasea pada wajah dan leher (Fitzpatrick, 2012).

Lesi DS ditandai dengan lesi kulit yang berwarna kekuningan, eritema ringan sampai berat, infiltrate beradang yang ringan, berminyak, bersisik tebal dan berkrusta. Lesi seperti ini sering dikenal sebagai pityriasis steatoides, sebagian besar pasien mengeluh rasa gatal terutama pada kulit kepala dan lubang telinga (Ervianti, 2008).

Letak lesi DS kadang sulit dibedakan dengan beberapa diagnosis banding dermatitis seboroik, yaitu psoriasis, dermatitis atopik, dermatitis kontak dan juga eritrasma misalnya pada kasus yang terjadi pada anak, lesi pada lipatan tubuh, atau lesi pada kepala. Oleh karena itu dibutuhkan pemeriksaan klinis yang cermat dengan memperhatikan tempat predileksi dari masing-masing kelainan tersebut (Berk, 2010).

\section{KESIMPULAN}

Berdasarkan hasil penelitian dan pembahasan dari kedua variabel yang diteliti, yaitu letak lesi dermatitis seboroik dengan angka kejadian dermatitis seboroik di Poliklinik Kulit dan Kelamin RSUD Dr. H. Abdul Moeloek Bandar Lampung, maka dapat disimpulkan sebagai berikut:

1. Diketahui distribusi frekuensi letak lesi dengan angka kejadian dermatitis seboroik terbanyak adalah seboroik badan sebanyak 47 orang (63\%).

2. Diketahui terdapat hubungan yang signifikan antara letak lesi dermatitis seboroik dengan angka kejadian dermatitis seboroik di Poliklinik Kulit dan Kelamin RSUD Dr. H. Abdul Moeloek Bandar Lampung dengan hasil $p=0,006$ $(p<0,05)$.

\section{SARAN}

1. Disarankan kepada pasien dermatitis seboroik di Poliklinik Kulit dan Kelamin RSUD Dr. $\mathrm{H}$. Abdul Moeloek Bandar Lampung untuk dapat menjaga kebersihan dalam mengelola penyakit dermatitis seboroik sehingga dapat mencegah timbulnya penyebaran lesi kulit dermatitis seboroik yang lebih parah.

2. Perlu dilakukan penelitian lebih lanjut dengan rancangan selain cross sectional dan jumlah sampel yang lebih banyak.

3. Diperlukan juga penelitian dan pembahasan yang lebih detail mengenai perbedaan letak lesi dermatitis seboroik dan bukan dermatitis seboroik.

\section{UCAPAN TERIMAKASIH}

Terimakasih saya ucapkan kepada Rumah Sakit Umum Daerah Dr. $\mathrm{H}$. Abdul Moeloek Bandar Lampung serta semua pihak yang telah mendukung pelaksanaan penelitian ini.

\section{DAFTAR PUSTAKA}

Ahmed, A., Leoan, A., Butler, D. C., \& Reichenberg, J. (2013). Qualityof-life effects of common dermatological diseases. Semin Cutan Med Surg3(2): 101-109.

Berk, T.(2010). Seborrheic dermatitis.Pharmacy \& Theurapetics 55 (35):348.

Burns, Breathnach, Cox, \& Griffiths, C.(2010). Rook's Textbook of Dermatology. Chichester: WileyBlackwell.

Cheong, W. K., Yeung, C. K., Torsekar, R. G., Suh, D. H., Ungpakorn, R., Widaty, S., \& Shih, I. H. (2015). Treatment of seborrhoeic dermatitis in Asia: a consensus guide. Skin appendage disorders 1(4) :187-196. 
Ervianti, E. (2008). Konsep terbaru dermatitis seboroik dan dandruff. New prespective of dermatitis. Surabaya: PKB IKK.

Fadila, M. N., Sibero, H. T., Wahyuni, A., \& Hamzah, M. S. (2014). Hubungan antara Dermatitis Seboroik dengan Kualitas Hidup Pasien di Rsud Abdul Moeloek Lampung. Jurnal Majority 3(6): 7.

Fitzpatrick. (2012). Seborrhea Dermatitis. Fitzpatrick's Dermatology in General Medicine. United States: The McGrawHill Companies.

Habif, T. P. (2016). Clinical Dermatology E-Book: A Color Guide to Diagnosis and Therapy. Hanover:Elsevier Health Sciences.

Hajar, S. (2015). Manifestasi Klinis Dermatitis Seboroik pada Anak. Jurnal Kedokteran Syiah Kuala 15(3): 175-178.

Harahap, M. (2015). IImu Penyakit Kulit. Jakarta : Hipokrates

Jacoeb, T. N. A. (2015). Ilmu Penyakit Kulit dan Kelamin. Jakarta: Badan Penerbit FKUI.

Plewig, G., Jansen, T. (2008). Fitzpatrick's Dermatology in General Medicine. New York: McGraw-Hill.

Riskesdas. (2007). Laporan Hasil Riset Kesehatan Dasar Nasional 2007. Jakarta: Badan Litbangkes Depkes RI.

Sampaio, A. L. S. B., Mameri, A. C. A., Vargas, T. J. D. S., Nunes, A. P., \& Carneiro, S. C. D. S. (2011). Dermatite seborreica. Anais Brasileiros de Dermatologia86(6): 1061-1074.

Selden, Travers, Vinson \& Meffert. (2014). (Medscape Reference). [Diunduh 14 September 2019]. Tersedia dari : https://ejournal.unsrat.ac.id/ind ex.php/eclinic/article/view/6823.

Schwartz, R. A., Janusz, C. A., dan Janninger, C. K. (2006). Seborrheic dermatitis. American Family Physicians74 (30) : 125. 